\title{
Gunilla Budde (dir.), Kapitalismus. Historische Annäherungen
}

Göttingen : Vandenhoeck \& Ruprecht, 2011, 191 p., 27,99€

\section{Guillaume Garner}

\section{(2) OpenEdition \\ Journals}

Édition électronique

URL : http://journals.openedition.org/ifha/7537

DOI : 10.4000/ifha.7537

ISSN : 2198-8943

Éditeur

IFRA - Institut franco-allemand (sciences historiques et sociales)

Référence électronique

Guillaume Garner, «Gunilla Budde (dir.), Kapitalismus. Historische Annäherungen », Revue de l'IFHA [En ligne], Date de recension, mis en ligne le 15 décembre 2013, consulté le 22 septembre 2020. URL :

http://journals.openedition.org/ifha/7537 ; DOI : https://doi.org/10.4000/ifha.7537

Ce document a été généré automatiquement le 22 septembre 2020.

(CIFHA 


\title{
Gunilla Budde (dir.), Kapitalismus. Historische Annäherungen
}

Göttingen : Vandenhoeck \& Ruprecht, 2011, 191 p., 27,99€

\author{
Guillaume Garner
}

La crise économique et financière que traverse le monde depuis 2008 aidant, les historiens redécouvrent le capitalisme comme objet historique, ou plutôt le découvrent, tant il vrai qu'en Allemagne (plus qu'en France), le concept a longtemps été vu avec une certaine suspicion en raison de la connotation négative qui lui est accolée depuis le milieu du XIXe siècle. Que le capitalisme ait été au centre des communications présentées à l'occasion du départ en retraite de Jürgen Kocka, éminent spécialiste de l'histoire sociale des XIXe et XXe siècles et considéré comme l'une des figures de proue de l'" école de Bielefeld ", n'a donc rien d'étonnant. Les huit contributions rassemblées dans ce volume se proposent d'éclairer quelques-unes des multiples facettes du capitalisme, dont le lecteur cherchera en vain une définition dans l'introduction qui ouvre ce volume, l'équivalence entre capitalisme et économie de marché n'ayant pas le caractère d'évidence qui lui est parfois prêté dans ce volume (par exemple p. 99 sous la plume de G.B.).

W. Lepenies aborde la spéculation financière à partir du célèbre roman de Balzac César Birotteau pour souligner à quel point l'absence de régulation permettait dans la première moitié du XIXe siècle des activités que les États se sont par la suite (et jusque dans les années 1980) efforcés de limiter. L'article d'H. Berghoff, consacré à l'irrationalité des marchés immobiliers et financiers aux États-Unis depuis trois décennies fait écho à cette première étude: l'un des facteurs essentiels de cette irrationalité réside dans le manque de profondeur chronologique des données dont disposent les agents des marchés financiers tout comme les ménages recourant aux crédits à la consommation, une mise en perspective de longue durée permettant par exemple de prévoir la crise des subprimes intervenue en 2007. Cette analyse argumentée permet par ailleurs de confirmer à quel point l'hypothèse de rationalité des acteurs, sur laquelle repose l'économie standard, est erronée. 
H.-U. Wehler reprend d'une certaine façon la thèse d'un Sonderweg allemand en soulignant que depuis le début du XIXe siècle et l'émergence d'une économie politique d'inspiration smithienne, le discours économique allemand, de List à l'école historique de l'économie politique, a été marqué par des réticences marquées à l'égard de l'économie de marché capitaliste avant que ne triomphe après 1945 ce que l'auteur appelle un "fanatisme du marché » d'inspiration néoclassique. En l'absence d'une étude comparative, par exemple avec la France, dont des travaux récents soulignent également l'hostilité au libre-échange, la thèse d'un Sonderweg allemand dans ce domaine semble cependant plus affirmée que prouvée.

U. Frevert se propose d'étudier les relations entre capitalisme et émotions en soulignant que, dès la fin du XIXe siècle, l'action et l'emprise sur les émotions ont été étudiées à des fins instrumentales, qu'il s'agisse de motiver une main-d'œuvre rétive aux conditions de travail qui sont les siennes dans les années 1880-1930 ou d'inciter, à travers le marketing et la publicité, les consommateurs à acheter de nouveaux biens de consommation. L'approche culturelle ici retenue conduit à des résultats stimulants et parfois à des interprétations moins convaincantes comme celle qui voit (p. 58-59) dans le dégoût exprimé dans les années 1880-1920 par les salariés envers leur travail moins les conséquences de leurs conditions de travail que celles d'un processus d'individualisation et d'affirmation de la subjectivité individuelle.

G. Budde reprend un thème cher à J. Kocka, à savoir les relations entre familles et capitalisme. Elle souligne à quel point, non seulement aux débuts du capitalisme industriel, mais également pendant la période des années 1880-1930 les relations familiales ont été déterminantes dans la mobilisation, la préservation et l'accumulation du capital, non seulement pour les petites et moyennes entreprises du Mittelstand, mais également pour de grands groupes tels que ceux articulés autour des familles Siemens et Stinnes.

G. Krämer pose la question de la compatibilité entre islam et capitalisme. Elle part pour cela de la fameuse thèse weberienne de l'éthique protestante du capitalisme, approche qui se révèle beaucoup plus encombrante que fructueuse: lisant que les marchands ibadites «ne pouvaient (...) pas développer un capitalisme industriel moderne dans le contexte du commerce caravanier transsaharien» (p.132), le lecteur se dit qu'à considérer cette thèse de Weber comme une clé de lecture universelle du capitalisme, on s'expose, si ce n'est à enfoncer des portes ouvertes, du moins à vérifier la théorie des rendements décroissants.

C. S. Maier s'interroge quant à lui sur la dimension spatiale du capitalisme. Selon lui, les débats sur cette question s'organisent autour d'une opposition entre une vision classique - représentée par Adam Smith et Karl Marx - selon laquelle le capitalisme est historiquement marqué par une expansion spatiale uniforme, dans laquelle les différences spatiales et territoriales jouent un rôle réduit, tandis que les théoriciens de l'impérialisme (de Lénine à Wallerstein) placent l'opposition entre centre et périphéries au centre de la dynamique du capitalisme. M. van der Linden, enfin, plaide pour une redéfinition du concept de classe ouvrière (Arbeiterklasse): selon lui, la parenté, postulée par K. Marx et M. Weber, entre capitalisme et libre travail salarié, doit être remise en cause, et il convient d'intégrer dans la conception du capitalisme et dans la définition de la notion de classe ouvrière d'autres formes d'exploitation, notamment l'esclavage, ou le travail non-marchand des femmes et des enfants. 
La contribution finale de J. Kocka est à lire comme une conclusion-commentaire des textes précédents. L'auteur y évoque des thèmes relativement peu abordés dans le volume, notamment la question de la variété des capitalismes et la problématique de l'exploitation des ressources naturelles, qui est effectivement la grande absente d'un recueil dont la lecture est dans l'ensemble très stimulante.

INDEX

Index chronologique : Neuere und Neueste Geschichte

Thèmes : Wirtschaftsgeschichte, Sozialgeschichte

\section{AUTEUR}

\section{GUILLAUME GARNER}

ENS Lyon/ UMR 5190 LARHRA 